\title{
8
}
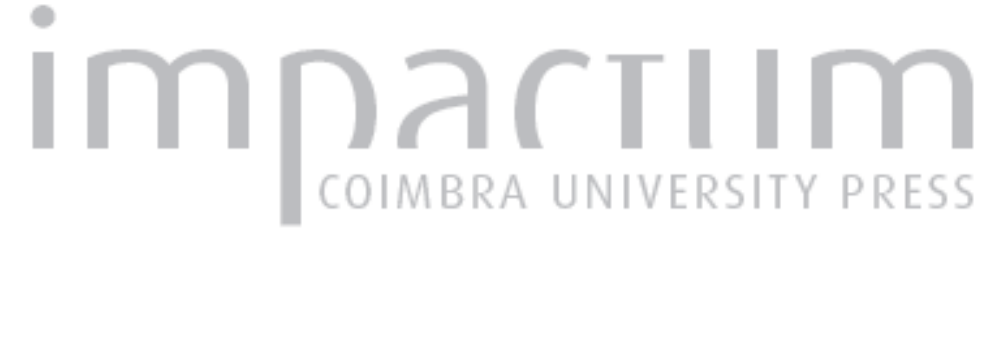

\section{Gosto e crítica nos ensaios de Hume}

Autor(es): $\quad$ Nascimento, Luís Fernandes dos Santos

Publicado por: Faculdade de Letras da Universidade de Coimbra, Instituto de Estudos Filosóficos

URL

persistente:

URI:http://hdl.handle.net/10316.2/35599

DOI:

DOI:http://dx.doi.org/10.14195/0872-0851_45_3

Accessed : $\quad$ 26-Apr-2023 16:18:25

A navegação consulta e descarregamento dos títulos inseridos nas Bibliotecas Digitais UC Digitalis, UC Pombalina e UC Impactum, pressupõem a aceitação plena e sem reservas dos Termos e Condições de Uso destas Bibliotecas Digitais, disponíveis em https://digitalis.uc.pt/pt-pt/termos.

Conforme exposto nos referidos Termos e Condições de Uso, o descarregamento de títulos de acesso restrito requer uma licença válida de autorização devendo o utilizador aceder ao(s) documento(s) a partir de um endereço de IP da instituição detentora da supramencionada licença.

Ao utilizador é apenas permitido o descarregamento para uso pessoal, pelo que o emprego do(s) título(s) descarregado(s) para outro fim, designadamente comercial, carece de autorização do respetivo autor ou editor da obra.

Na medida em que todas as obras da UC Digitalis se encontram protegidas pelo Código do Direito de Autor e Direitos Conexos e demais legislação aplicável, toda a cópia, parcial ou total, deste documento, nos casos em que é legalmente admitida, deverá conter ou fazer-se acompanhar por este aviso.

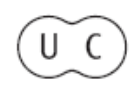




\section{REVISTA FILOSÓFICA DE COIMBRA}

vol. 23 - número 45 - março 2014

vol. 23 - número 45 - março 2014 Fundação Eng. António de Almeida

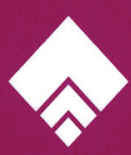




\section{GOSTO E CRÍTICA NOS ENSAIOS DE HUME}

\section{LUÍS FERNANDES DOS SANTOS NASCIMENTO²}

Resumo: A partir da análise de alguns ensaios de Hume, tais como Da simplicidade e refinamento na arte de escrever e Do surgimento e progresso das artes e ciências, o presente texto busca examinar a relação apresentada nesses textos entre as noções humanas de gosto e de crítica.

Palavras-chave: Hume - ensaio - gosto - crítica

Abstract: From the analysis of some of Hume's essays, such as Of simplicity and refinement in writing and $O f$ the rise of progress of arts and sciences, the present paper tries to look into the relationship between the humean's concepts of taste and criticism as presented in those essays.

Key Words: Hume - essay - taste - criticism

“Um gosto legítimo e justo não pode ser gerado, criado, concebido ou produzido sem o trabalho e as penas da crítica"

Shaftesbury ${ }^{3}$

Nas linhas que abrem um ensaio chamado Da simplicidade e do refinamento na arte de escrever (Of simplicity and refinement in writing), David Hume afirma:

1 Originalmente, este texto fez parte de uma pesquisa realizada em nível de pós-doutorado entre 2007 e 2008 (intitulada A questão do gosto na filosofia britânica do século XVIII: Shaftesbury, James Harris e David Hume), pesquisa que contou com o auxílio da FAPESP e com a supervisão da Professora Doutora Maria Lúcia Cacciola, da Universidade de São Paulo/Brasil.

2 Professor do Departamento de Filosofia e Metodologia das Ciências da Universidade Federal de São Carlos, Brasil.

3 SHAFTESBURY, Miscellaneous reflections. In: Characteristics of men, manners, opinions, times, p.208, vol.2. Os grifos e itálicos são do próprio Shaftesbury. 
"A arte de escrever com finura consiste, de acordo com o Senhor Addison, em sentimentos que são naturais sem serem óbvios. Não pode haver definição mais justa e mais concisa dessa arte."4

Como nos mostra a edição dos Ensaios organizada por Eugene F. Miller, ao mencionar o nome de Joseph Addison, Hume refere-se ao Spectator de número 345 , datado de 5 de abril de $1712^{5}$. Em uma nota à tradução brasileira desse mesmo livro de Hume, Márcio Suzuki e Pedro Paulo Pimenta acrescentam que se trata de um texto no qual Addison comenta o Paraíso Perdido, de Milton. Para o autor do Spectator, a obra do célebre poeta inglês é uma prova de que o refinamento na escrita deve provir de uma naturalidade que jamais se confunde com a obviedade, tese que é recuperada por Hume no trecho acima citado. No entanto, como nos lembram os tradutores brasileiros, há algo no texto do filósofo escocês que não se encontra no de Addison, a saber: a palavra "sentimento" (sentiment). Esse detalhe é fundamental para a compreensão do que é para Hume "escrever com simplicidade e refinamento", sobretudo quando consideramos a distinção que o filósofo estabelece entre os termos sentiment e feeling:

O que faz a diferença do sentiment em relação ao feeling é que ele é uma reflexão, um juízo, uma opinião e, ao mesmo tempo, a expressão deles. Somente com a compreensão desse significado implícito de 'sentimento', a 'definição' que Hume propõe para a arte de escrever passa a fazer sentido: ela consiste [na expressão] de sentimentos naturais que não são óbvios. ${ }^{6}$

Termo comumente ligado às afecções e à apreensão do mundo sensorial, feeling (muitas vezes vertido por sentimento) se distinguiria do inglês sentiment dada a relação que esse último estabeleceria, na letra de Hume, com o âmbito mental e na medida em que pressuporia a atividade de julgar ${ }^{7}$. Temos

${ }^{4}$ HUME, D. A arte de escrever ensaios, p.157, grifo nosso.

5 HUME, D. Of simplicity and refinement in writing. In: Essays moral, political and literary, p.191, nota número 1.

6 PIMENTA, P.P. e SUZUKI, M. Nota 182. In: A arte de escrever ensaios, p.157. A edição brasileira segue aquela editada por Eugene F. Miller.

7 Desse ponto de vista, o sentiment não se limitaria a apenas sentir (to fell), mas pressuporia um juízo, avaliação e mesmo crítica daquilo que se sente. Daí seu vínculo com o gosto, como nos explicam Márcio Suzuki e Pedro Paulo Pimenta no item Taste (gosto) que escrevem para o Glossário que acompanha a edição que fazem dos ensaios de Hume: “(...) para Hume, o gosto é exigido não apenas para julgar as belezas naturais, mas também as chamadas belezas artificiais (produzidas pelas artes, música e literatura) e morais (o caráter e os modos dos indivíduos) (...). O gosto é assim, junto com o sentimento, a 'fundação tanto da moral quanto da crítica', como afirma Eugene F. Miller em sua edição dos Ensaios (Indianápolis: Liberty Fund, 2005, p.226)”. 
então uma primeira definição do que vem a ser a arte de escrever ou a bela escritura (fine writing) para o filósofo escocês: trata-se da expressão de opiniões, juízos ou reflexões (isto é: trata-se de um sentiment), que, embora soe natural, não é óbvia. Mas qual é exatamente a diferença entre o óbvio e o natural na arte de escrever? A fim de responder a essa questão, o filósofo escocês distingue o que ele chama de dois gêneros (kinds) de excessos cometidos pelos escritores. Um deles é o exagero de simplicidade ou de obviedade. O outro é o excesso de refinamento e ornamentação, que torna o texto artificial.

Explicando o primeiro gênero de exagero, Hume dirá que "sentimentos meramente naturais não afetam a mente com nenhum prazer, nem parecem dignos de nossa atenção"8 e ilustra o seu argumento com os seguintes exemplos: as piadas de um barqueiro, as opiniões de camponês ou as grosserias de cocheiro "são todas elas naturais e desagradáveis"9. "Que comédia insípida não teríamos se copiássemos, fiel e integralmente, o futrico de uma mesa de chá?" 10 , pergunta o filósofo escocês? A mera cópia da "vida chã" (low life), completamente desprovida das graças e dos ornamentos que a arte lhe empresta, não pode agradar. Pior ainda: a representação das coisas tal como elas são, é tediosa e insípida - não chama a atenção de ninguém. Óbvio é então aquele texto que não apresenta nada de novo, que se atém aos limites do "meramente natural" (merely natural) e, por essa razão, não pode tocar (strike) a mente. Somente as "pinceladas" (strokes = golpes) do artista podem dar vida e força ao que é ordinário e corriqueiro. São as "cores tão inimitáveis" 11 de Cervantes que fazem com que um simplório camponês como Sancho Pança se transforme em um grande personagem, capaz de entreter e agradar a todos. De acordo com Hume, assim como o autor de Dom Quixote, todos os escritores, na medida em que pretendem chamar a atenção de seu público, devem evitar o exagero de simplicidade (ou obviedade) e desenvolver algo de original. Mesmo os oradores, os filósofos e os críticos têm de levar isso em conta: para ser convidativo e ter sabor (relish), um discurso precisa trabalhar com algum grau de novidade, do contrário, acrescenta Hume, seu autor "pode ser correto, mas jamais será agradável"12. Por outro lado, aqueles escritores que fazem de suas obras o resultado de uma arte "meramente surpreendente" 13 e que desprezam por completo tudo o que é comum e ordinário, também cometerão um excesso: "Desenhar quimeras não é, propriamente falando, copiar ou imitar. Perde-se a justeza da repre-

8 HUME, D. A arte de escrever ensaios, p.157.

9 HUME, D. A arte de escrever ensaios, p.157.

10 HUME, D. A arte de escrever ensaios, p.157.

11 HUME, D. A arte de escrever ensaios, p.158.

12 HUME, D. A arte de escrever ensaios, p.158.

13 HUME, D. A arte de escrever ensaios, p.158. 
sentação, e é desagradável para a mente ver um quadro que não tenha semelhança com original algum" 14 . Eis aí o segundo gênero de exagero na arte de escrever: o que é "meramente surpreendente", aquilo que seria novo ou original por completo, é desagradável justamente porque carece de qualquer relação com algo anterior: uma origem, um modelo no qual se assemelha. $\mathrm{O}$ desenho de uma quimera é insípido e desinteressante, pois não oferece a possibilidade de uma comparação com nada que se apresente na natureza. Se não lhe for dada a chance de comparar o quadro que contempla com alguma coisa que já conhece, o público não o considerará belo. $\mathrm{O}$ argumento de Hume visa mostrar que a beleza de uma arte depende dessa comparação: os artistas necessitam trabalhar com alguns elementos comuns (conhecidos de todos), sem os quais suas produções se tornam enfadonhas. Paradoxalmente, o excesso de originalidade leva à perda de uma origem, o que, por sua vez, impossibilita a apreciação da obra e confundem o olhar e o julgamento do espectador. $\mathrm{O}$ mesmo pode ser dito de escritores que abusam da linguagem e exageram nos ornamentos e no emprego de palavras desconhecidas da grande maioria do público:

Expressões incomuns, exibição ostensiva de engenho, símiles incisivos, inflexões epigramáticas, especialmente quando ocorrem com demasiada frequência, mais desfiguram que embelezam o discurso. Assim como o olho, ao examinar um edifício gótico, é distraído pela multiplicidade de ornamentos e perde o todo em virtude da minuciosa atenção que dedica às partes, também a mente, ao estudar um trabalho abarrotado de engenho, fica cansada e descontente com esse esforço constante de brilhar e surpreender. ${ }^{15}$

Podemos notar que há no texto de Hume dois momentos que se complementam. No primeiro ele afirma que o exagero de refinamento e engenho na arte de escrever acarreta a perda de uma referência comum ou natural (o desenho da quimera é o exemplo dado pelo filósofo escocês quando explica esse caso). No segundo, diz que esse mesmo exagero faz com que não se possa apreender a totalidade da obra, que se esvai em meio aos infinitos ornamentos apresentados pelo artista (Hume recorre aqui à imagem do edifício gótico). Os exemplos do desenho da quimera e do edifício gótico mostram dois aspectos de um mesmo argumento, a saber: o uso desmedido do refinamento faz com que um texto se torne uma obra incompleta (na qual a totalidade é obscurecida pelas partes) e, com isso, ganha ares de estranheza e monstruosidade - afasta-se do natural. A profusão de detalhes, o abuso no emprego de expressões e construções incomuns confunde a apreciação do

\footnotetext{
14 HUME, D. A arte de escrever ensaios, p.158, grifo nosso.

15 HUME, D. A arte de escrever ensaios, p.158.
} 
público e o impede de reconhecer o que ali haveria de novo. Na ânsia de inovar, o autor que quer surpreender e escreve como se estivesse construindo um edifício gótico acaba por obter um efeito muito similar ao do escritor "meramente natural": causa tédio e aborrece aquele que o lê.

Portanto, para bem escrever é preciso saber mesclar o óbvio à novidade. Assim como a produção, o julgamento da obra depende das relações que se estabelece entre ordinário e surpreendente. Ignorar um desses dois extremos significa desconhecer aquilo que torna a arte de escrever bela e fina. A beleza nasce da proporção e da justeza entre elementos comuns e inusitados: entre a simplicidade e o refinamento. Tanto na expressão da obviedade chã (low) quanto nas obras que apresentam uma profusão de ornamentos não há lugar para o exercício mental - em ambos os casos, nada toca (strike) a mente. Os dois gêneros de exagero dificultam as comparações que possibilitam os juízos e as análises que identificam a beleza de um texto. Assim, a questão da "arte de escrever com finura" (a fine writing) passa a ser a de como mesclar o "meramente natural" com engenhoso ou surpreendente. A esse respeito, Hume diz:

"Não há assunto mais copiosamente tratado pelo saber crítico do que a justa mistura de simplicidade e refinamento na arte de escrever e, por isso, para não me perder num campo tão vasto, restringir-me-ei a umas poucas observações gerais sobre esse tópico."16

Nesse trecho, que constituí um pequeno parágrafo de Da simplicidade e do refinamento na arte de escrever, Hume nos mostra que tudo o que até então afirmara nesse ensaio era moeda corrente entre os críticos, ou seja: a tese de Addison segundo a qual a escrita fina tem de ser natural sem ser óbvia e que, portanto, deve misturar simplicidade e refinamento, já é (no momento em que Hume redige seu ensaio) um argumento conhecido por todos e, nesse sentido, ele é óbvio para aqueles que se dedicam à questão da arte de escrever. Com a passagem acima citada, o filósofo escocês deixa claro ao seu leitor que está trabalhando com uma idéia bastante difundida e reconhecida pelos críticos, e é a partir dessa "obviedade" (que não tem nada de original) que ele irá agora introduzir certas "pinceladas" (strokes) de novidade e refinamento. Como o próprio Hume diz, trata-se de algumas "observações gerais sobre o tema", mais precisamente, de três comentários a respeito da arte de escrever. No primeiro deles, afirma:

"Em primeiro lugar observo: ainda que se deva evitar os dois gêneros de excesso, e ainda que se deva estudar o meio-termo próprio a cada obra, esse meio-termo não reside num ponto, mas admite uma considerável latitude."17

16 HUME, D. A arte de escrever ensaios, p.159, grifo nosso.

17 HUME, D. A arte de escrever ensaios, p.159, em itálico no original. 
Não há como determinar com precisão um meio-termo para a mistura entre simplicidade e refinamento e diferentes artistas podem atingir o mesmo grau de elegância na escrita a partir de combinações distintas de obviedade e novidade. "Todo esse intervalo pode ser preenchido por poetas diferentes entre si", acrescenta Hume, "mas cada um deles igualmente admirável em seu estilo e maneiras peculiares"18. Analisar a beleza de um texto exige que se considere o modo como a obra foi composta: leva em conta as particularidades e as características próprias de seu autor. O crítico tem então de entender que existem várias manifestações ou medidas para a mesma ideia de equilíbrio entre simplicidade e refinamento. Afirmação essa que pode parecer um tanto paradoxal, uma vez que nos leva a admitir que esse "meio-termo" defendido por Hume é, concomitantemente, algo que se repete ou que sempre é buscado pelos mais diferentes poetas e escritores, mas que jamais é idêntico para cada um deles. Ou seja: a ideia de "meio-termo" entre simplicidade e refinamento é (ao mesmo tempo) universal (já que todos os escritores a consideram) e particular (visto que cada artista encontrará a sua própria maneira de combinar obviedade e novidade). Esse tema fica ainda mais explícito quando lemos a segunda observação proposta por Hume:

Minha segunda observação sobre esse tópico é que é muito dificil, senão impossivel, explicar em palavras onde está o justo meio-termo entre os excessos de simplicidade e refinamento, ou dar alguma regra pela qual possamos conhecer os limites entre o defeito e a beleza. ${ }^{19}$

Mais uma vez Hume trabalha com um paradoxo: a explicação de onde está localizado o meio-termo entre simplicidade e refinamento tem necessariamente de pressupor o fato de que é impossível fixar com precisão esse ponto de equilíbrio. Não é por acaso que o filósofo escocês começará o seu comentário de uma maneira negativa, isto é: mostrando o que não deve ser feito e criticando aqueles que buscaram dar ao tema uma resposta acabada e conclusiva. De acordo com Hume, Fontenelle, em sua Dissertação sobre as pastorais ${ }^{20}$, esforçou-se para fixar um meio-termo que fosse conveniente a esse tipo de poesia e, no entanto, acrescenta o filósofo escocês, quando lemos as "pastorais" que esse autor escreveu constata-se que ele exagerou no refinamento ${ }^{21}$. Os poemas de Fontenelle opõem-se ao que é prescrito por sua

18 HUME, D. A arte de escrever ensaios, p.159.

19 HUME, D. A arte de escrever ensaios, p.159, em itálico no original.

20 HUME, D. Of simplicity and refinement in writing. In: Essays moral, political and literary, p.194.

21 HUME, D. "Os sentimentos de seus pastores são muito mais adequados às toilettes de Paris do que às florestas da Arcadia". A arte de escrever ensaios, p.160. 
crítica e exageram nos ornamentos. Sem que o diga explicitamente, Hume sugere que é o modo com que o francês trata a poesia em Dissertação sobre as pastorais (procurando estabelecer para ela normas e regras bem determinadas) que o torna um mau escritor. O "falso gosto"22 (false taste) que o leitor encontra em sua poesia é o mesmo que orienta os seus juízos e reflexões acerca da literatura. Ao recorrer às obras de Fontenelle, Hume visa sustentar o argumento a partir do qual não há como estabelecer regras universais para a arte de escrever. Mesmo um gênero literário específico (tal como o pastoral) pode ser produzido de diversas maneiras, de acordo com o modo com que o seu autor mistura simplicidade e refinamento, obviedade e novidade. Quando ignora esse caráter flexível da arte de escrever, o crítico perde as particularidades das obras que examina e acaba por desprezar aquilo que as torna belas:

Nenhuma crítica pode ser instrutiva se não desce às particularidades e se não é repleta de exemplos e ilustrações. Por toda a parte se reconhece que a beleza, assim como a virtude, está no meio-termo; a grande questão, no entanto, é onde se localiza esse meio-termo, e ela jamais pode ser suficientemente elucidada por raciocínios gerais. ${ }^{23}$

A atividade da crítica demanda o equilíbrio entre dois domínios: o geral e o particular. As observações que Hume faz nesse ensaio sobre a arte de escrever são (como ele mesmo afirma) gerais, porém "descem às particularidades", para usar uma expressão empregada no trecho acima citado. Ou seja: Hume ilustra o seu texto, exemplifica e recorre a casos particulares quando deseja explicar aquilo que, como ele mesmo diz, "não pode ser explicado por palavras". Portanto, recorrer a Fontenelle é uma maneira de tornar claro algo que de outro modo não poderia ser dito, isto é: o fato de não haver como determinar um meio-termo fixo para a arte de escrever. No texto de Hume, o autor francês é um exemplo particular que ajuda a corroborar a "observação geral" que ali é proposta. Por oposição ao false taste de Fontenelle, o crítico dotado de um "gosto verdadeiro" sabe que há um momento em que a elaboração do seu próprio argumento exige que ele vença sua natural postura professoral, que combata a tentação de tudo explicar e passe a indicar - a ilustrar. Quando apenas trabalha com regras gerais e não oferece exemplos de casos particulares, o texto crítico acaba por assemelhar-se à imagem do desenho da quimera ou à do edifício gótico, ou seja: perde por completo o contato com o objeto que examina e sobre o qual discorre, tornando-se ou confuso ou cansativo para aquele que o lê.

22 HUME, D. A arte de escrever ensaios, p.160.

23 HUME, D. A arte de escrever ensaios, p.160, grifo nosso. 
Por outro lado, a análise que se detém unicamente em particularidades, que não faz outra coisa senão parafrasear e copiar os autores e temas que examina, também não poderá ser considerada como crítica, pois, a exemplo daquelas que se perdem em observações e regras gerais, ela nada diz da questão que examina. É preciso combinar universalidade e particularidade: os argumentos gerais têm sempre de ser acompanhados de casos que os ilustram. E curioso notar que o modo como Hume elabora sua obra atesta essa sua tese. O próprio estilo e a maneira com a qual esse ensaio ( $D a$ simplicidade e do refinamento na arte de escrever) é escrito podem ser entendidos como aquele elemento particular que aliado às observações gerais ali introduzidas, fazem dele um texto genuinamente crítico. Em outros termos: esse ensaio é (ele mesmo) a melhor ilustração do que pretende defender. Diferentemente de Fontenelle, Hume apresenta e aplica o que entende ser o meio-termo na arte de escrever. Sua teoria é, ao mesmo tempo, um exemplo do que sustenta: ao defender a ideia de que o bom escritor deve aliar obviedade e novidade, ele a pratica quando toma o tema do meio-termo (conhecido de todos os críticos) e o trata de um novo modo (descartando a possibilidade determinação precisa da mistura entre simplicidade e refinamento). A última observação de Hume retoma esse mesmo ponto e acrescenta uma ressalva ao que foi dito nas duas anteriores:

"Proponho como terceira observação sobre esse assunto que devemos nos precaver mais contra o excesso de refinamento do que contra o de simplicidade; e isso porque o primeiro excesso é tanto menos belo quanto mais perigoso do que o último." 24

Ora, mas por que o excesso de refinamento é menos belo e mais perigoso do que o de simplicidade? A primeira parte da resposta de Hume é a seguinte: ele é menos belo, porque é mais intenso. Textos exageradamente refinados representam uma violência à mente - uma grande perturbação que, em pouco tempo, transforma-se em constrangimento e irritação. A profusão de ornamentos e palavras requintadas pode surpreender em um primeiro momento, mas logo cansa. Mais uma vez, o filósofo escocês recorre a exemplos para ilustrar suas observações. Os epigramas de Marcial são por demais refinados e, por essa razão, não resistem a uma segunda leitura: ao reler a primeira linha, a mente "recorda o todo" 25 e já se sente cansada com a lembrança dos abusos cometidos pelo poeta. Ao contrário, a releitura de uma obra que pende para a simplicidade é tão fresca (fresh) "quanto a primeira (leitura)"26. Esse é o caso de Catulo e do poeta irlandês Thomas Parnell. Com os livros,

\footnotetext{
24 HUME, D. A arte de escrever ensaios, p.160.

25 HUME, D. A arte de escrever ensaios, p.161.

26 HUME, D. A arte de escrever ensaios, p.161.
} 
acrescenta Hume, ocorre o mesmo que com as mulheres, "nas quais uma certa sobriedade nos modos e nos trajes é mais atraente que todo aquele esplendor de cosméticos, ares afetados e vestidos, que pode deslumbrar o olhar, mas não conquista o afeto (but not reaches the affections = não alcança a afeição)"27. Em si mesmo, o refinamento é bastante efêmero - seu tempo de duração é equivalente à intensidade com que arrebata a mente. Se, como explica Hume em outro ensaio chamado Do padrão de gosto (Of standard of taste), o reconhecimento da beleza de um determinado objeto depende do juízo acurado daquele que o contempla e analisa ${ }^{28}$, então um texto que não permite ao seu leitor a possibilidade de um cultivo ou de releituras, que perturba e cansa o seu público, não poderá ser tomado como belo. "Um verdadeiro gênio, ao contrário [do falso], quanto mais perdura e mais se difunde a sua obra, mais sincera é a admiração que encontra" 29 . Os golpes ou pinceladas de gênio (strokes of genius) não têm nada a ver com a violência à qual o exagero de refinamento submete a mente. Verdadeiros artistas não querem extasiar o seu público, mas oferecer-lhe um prazer duradouro, algo que pode ser objeto de um cultivo ${ }^{30}$. De uma certa maneira, os grandes escritores já nascem clássicos: sua duração (ou "perduração") está dada desde o momento em que conseguem combinar de modo elegante simplicidade e refinamento. Uma vez que não exagerarem nas novidades e nos ornamentos, suas obras serão belas e sempre guardarão um frescor (fresh) que os mantém vivos e atuais.

Em segundo lugar, para além do fato de ser menos belo, Hume afirma que o excesso de refinamento é mais perigoso do que o de simplicidade, pois é aquele que com mais frequência os homens de letras tendem a cair. Artistas são naturalmente propensos a artifícios. Assim, necessitam tomar mais cuidado com esse gênero de abuso do que com o outro. Mas o perigo não é apenas restrito a atividade dos escritores, também os leitores podem começar a pensar que a ostentação e o exagero de engenhosidade são as marcas características da boa escritura. "Leitores ordinários", diz-nos Hume, "impressionam-se fortemente com ele (o refinamento) e falsamente imaginam ser este o modo mais difícil quanto mais excelente de escrever"31. A

27 HUME, D. A arte de escrever ensaios, p.161.

28 Nesse célebre texto, Hume escreve: "Perfeita serenidade da mente, concentração de pensamento, devida atenção ao objeto: se qualquer uma dessas circunstâncias faltar, nosso experimento será falacioso, e seremos incapazes de julgar a beleza geral e universal". HUME, D. A arte de escrever ensaios, p.178.

29 HUME, D. A arte de escrever ensaios, p.178.

30 Tal como é afirmado em Do padrão do gosto: "O mesmo Homero que agradava em Atenas e Roma há dois mil anos ainda é admirado em Paris e em Londres". HUME, D. A arte de escrever ensaios, p.178

31 HUME, D. A arte de escrever ensaios, p.161. 
leitura da obra de um autor excessivamente refinado pode comprometer e prejudicar o gosto dos seus leitores, sobretudo o dos mais jovens que, diante da ostentação e do engenho de tal obra, os tomarão como um modelo de escrita. Cabe então ao crítico chamar a atenção para os malefícios desse tipo de literatura.

Existe ainda uma razão histórica para que Hume prefira a simplicidade ao refinamento. De acordo com o filósofo escocês, o cuidado com as ostentações e ornamentos na escrita é uma preocupação peculiar à sua época, "porque é o extremo em que os homens mais tendem a cair depois que as letras fizeram algum progresso e depois que surgiram escritores eminentes em toda espécie de composição" ${ }^{32}$. Tal constatação pressupõe não somente a compreensão do momento em que se vive (o conhecimento das características da época presente), mas também o entendimento de um percurso pelo qual a literatura e as artes em geral são propensas a seguir: depois de um período em que o mundo erudito atinge uma certa maturidade, é bem provável que se chegue a uma época em que os autores e o público exagerem no refinamento. É tendo em vista tal ideia de "percurso" ou "história" da erudição (learning) que Hume pode dizer que os artistas de um futuro muito próximo (entre eles, os escritores de seu tempo) privilegiarão os ornamentos, o uso de termos incomuns e de todo tipo de recurso que possa destacar seu engenho e originalidade. Daí, a importância de sua advertência: é preciso priorizar a simplicidade, sobretudo porque, na época em que escreve Hume, o gênero simples não é considerado como o mais adequado a um bom escritor. Dito isso, o filósofo escocês termina o ensaio Da simplicidade e do refinamento na arte de escrever.

Como dissemos, essa recomendação que encerra o referido texto de Hume está baseada na ideia de que existem certas tendências que frequentemente se repetem na formação e no desenvolvimento da cultura e da erudição humanas. Graças a essa concepção de movimento ou história da erudição, o filósofo escocês pode supor (e, de certo modo, arriscar uma previsão) qual será o próximo passo do desenvolvimento da literatura. Esse mesmo argumento é explicitado em outro texto que compõe sua coletânea de ensaios: Do surgimento e do progresso das artes e ciências (Of the rise and progress of arts and sciences). De acordo com esse ensaio, é muito mais fácil determinar a origem e o desenvolvimento da história civil do que o surgimento e o progresso da história da erudição. $\mathrm{O}$ estudo que se dedica à primeira sempre estará mais seguro do seu sucesso do que aquele que busca entender o percurso que segue a erudição: "não há assunto que requeira mais cautela em nosso proceder" 33 , diz Hume a respeito da história das artes e ciências.

32 HUME, D. A arte de escrever ensaios, p.161.
33 HUME, D. A arte de escrever ensaios, p. 85. 
Diferentemente do que ocorre com as causas que atuam na vida civil (paixões como a avareza, a amizade, o amor, a ambição, a honra, a vergonha, a gratidão e a vingança ${ }^{34}$ ), é muito difícil determinar o que move o progresso no âmbito das letras:

Aqueles que cultivam as ciências em qualquer estado são sempre pequenos em número. A paixão que os governa é limitada, seu gosto e juízo delicados e facilmente pervertidos. Portanto, o acaso ou as causas secretas e desconhecidas têm de ter uma grande influência no surgimento e no progresso de todas as artes refinadas. ${ }^{35}$

"Há certamente algo de acidental no surgimento das artes em qualquer nação" 36, afirma Hume em uma passagem de Da eloquência que em muito lembra a acima citada. No entanto, apesar de tanta imprecisão e da forte presença do acaso, é ainda possível encontrar um mínimo de fixidez capaz de viabilizar a ideia de uma "história dos progressos das artes e ciências". Embora sejam sempre poucos aqueles que se ocupam do conhecimento, eles existem em todas as nações e épocas da humanidade. Isso mostra que há susceptibilidade universal (dos homens em geral) às obras de eruditos que vai além do acaso que reina nos motivos que as impulsionam e as originam:

"A questão acerca do surgimento e do progresso das artes e ciências não é, pois, questão que diz respeito ao gosto, gênio e espírito de uns poucos, mas de todo o povo e pode, portanto, até certo ponto ser explicada por causas gerais." 37

De acordo com Hume, o gosto de um povo é como um material bruto a ser formado pelas mãos de poucos eruditos. E é essa possibilidade de formação (latente em todos as pessoas das mais diversas épocas e nações) que permite uma análise sobre o tema de um progresso nas artes e ciências. Ou seja: quando se reconhece que o gosto não é um tema inteiramente casual ou acidental, encontra-se aquilo que nele é geral. Mais ainda: ao detectar-se o elemento universal das questões que envolvem o juízo da beleza, pode-se também identificar vários casos particulares em diferentes países e períodos históricos. É possível comparar exemplos, extrair deles observações e perscrutar (to trace $=$ traçar) um movimento, tendência ou padrão a partir do qual as artes e ciências se formam. Assim como no ensaio Da simplicidade e do refinamento na arte de escrever, em Do surgimento e do progresso das artes e ciências Hume apresenta considerações gerais que são funda-

34 A esse respeito ver também o ensaio Da eloquência. In: HUME, D. A arte de escrever ensaios, pp. 71-82.

35 HUME, D. A arte de escrever ensaios, p. 85.

36 HUME, D. A arte de escrever ensaios, p. 78.

37 HUME, D. A arte de escrever ensaios, p. 85. 
mentadas por exemplos particulares: ele fala de diferentes épocas e modelos políticos, compara gregos com romanos, romanos com modernos, chineses com egípcios, franceses com ingleses etc. Em seu argumento há sempre essa relação de complementaridade entre uma esfera particular e outra universal. Os exemplos usados por Hume só podem ser vinculados por um raciocínio mais abrangente, que vai além da mera particularidade. Por sua vez, juízos gerais que ignoram as ocorrências particulares tornam-se por demais abstratos. Uma regra universal que não se apoia em casos que a ilustram inevitavelmente fracassará - como vimos, esse foi o grande erro de Fontenelle.

É então possível estabelecer um padrão para o gosto, embora nunca se possa encontrar para ele uma regra fixa ou bem determinada. Trata-se antes de uma regra flexível, capaz chegar a normas gerais que ainda guardem muito da particularidade dos exemplos em que se apoia e, por isso, afasta-se da abstração com a qual se perderia toda peculiaridade que se deve considerar ao julgar um objeto como belo. Para escrever com finura, é necessário que o homem de letras não se perca em argumentos e juízos meramente abstratos, que esteja consciente desse caráter flexível do gosto, que saiba identificar qual é a combinação de simplicidade e refinamento que melhor se adequa não apenas ao assunto geral sobre o qual discorre, mas também à época em que vive. Como nos diz Hume, escrever bem na Modernidade exige que se saiba que este momento em particular privilegia o refinamento e, por isso, seria recomendável ao autor moderno que buscasse o seu equilíbrio na simplicidade. Contudo, a própria consideração do que é peculiar ao tempo presente exige que o escritor tenha uma boa noção dos desenvolvimentos e progressos das artes e ciências, dos temas e questões que as constituem, dos modos ou maneiras com que se manifestaram em épocas e nações distintas, do contrário o próprio escritor não saberia em que ponto ou momento dessa mesma "história" ele se encontra. Enfim, a arte de escrever com finura exige a atividade crítica. Sem ela não há como comparar e atentar para a particularidade de diferentes exemplos, formular considerações gerais a partir deles, distinguir o óbvio da novidade, perguntar-se pela forma e o modo que melhor se adaptariam aos conteúdos que se deseja exprimir, e nenhum escritor de gosto obteria êxito sem antes ser um bom juiz dos temas aos quais se dedica.

\section{Bibliografia}

BROADIE, A. The scottish enlightenment. Edimburgo: Birlinn, 2001

CRUZ, F.O.S.S. As condições de possibilidade da ciência da natureza humana: crítica da metafísica e ciência do homem. São Paulo: Tese de doutorado apresentada ao Departamento de Filosofia da Universidade de São Paulo, 2007. 
HUME, D. Essays moral, political and literary. Editado por Eugene F. Miller. Indianapolis: Liberty Fund, 1987. Arte de escrever ensaios. Tradução de Márcio Suzuki e Pedro Paulo Pimenta. São Paulo: Iluminuras, 2011. An inquiry concerning human understanding. Oxford: Oxford University Press, 1999.

HUTCHESON, F. An inquiry into the original of our ideas of beauty and virtue (1726). Hildesheim: Georg Olms, 1990.

JONES, P. Hume's sentiments - their ciceronian and french context. Edimburgo: Edinburgh University Press, 1982.

PIMENTA, P.P. A imaginação crítica - Hume no século das Luzes. Rio de Janeiro: Azougue, 2012.

SHAFTESBURY (Anthony Ashley Cooper), Characteristics of men, manners, opinions, times. Editado por Philip Ayres. Oxford: Clarendon Press, 1999, Vol. 1 e 2.

SUZUKI, M. "O ensaio e a arte de conversar". In: HUME, D. Arte de escrever ensaios. Tradução de Márcio Suzuki e Pedro Paulo Pimenta. São Paulo: Iluminuras, 2011. 
